2 Design and Evaluation of a Tethered, Open Port Sampling

\title{
Chemical Analysis
}

5 Courtney L. Walton ${ }^{1}$, Vilmos Kertesz ${ }^{1}$, John F. Cahill ${ }^{1}$

6

$7 \quad{ }^{1}$ Oak Ridge National Laboratory, Oak Ridge, TN 37831-6131, USA

8

9

10 *Corresponding Author:

$11 \quad$ John F. Cahill

12 Mass Spectrometry and Laser Spectroscopy Group

13 Chemical Sciences Division

14 Oak Ridge National Laboratory, Oak Ridge, TN 37831-6131

15 E-mail: cahilljf@ ornl.gov

16 Phone: $865-574-4878$ 
In order for the tethered, open port sampling interface (TOPSI) to operate correctly solvent containing the analyte must be pulled from the TOPSI capillary into both the ionization source (IS) capillary and into the vacuum region. If considering a TOPSI system containing only one fluid (solvent) there are six possible arrangements of flow resistance through the three capillaries (Table 6 S1).

Table S1. The six possible arrangements of flow resistance through the three capillaries (TOPSI, vacuum, ion source) of the TOPSI system. Red highlighted arrangements indicate arrangements that are unlikely to yield functioning TOPSI designs.

\begin{tabular}{c|c|c|c}
$\begin{array}{c}\text { Arrangement } \\
\#\end{array}$ & Resistance in Capillaries when Filled with Solvent (greatest to least) \\
\hline 1 & IS & Vacuum & TOPSI \\
2 & IS & TOPSI & Vacuum \\
3 & Vacuum & TOPSI & IS \\
4 & Vacuum & IS & TOPSI \\
5 & TOPSI & Vacuum & IS \\
6 & TOPSI & IS & Vacuum
\end{tabular}

Arrangement 3 is difficult to achieve due to the diameters of capillaries best suited for ionization sources. In arrangements \#4 with the vacuum having higher resistance than the IS, the result is an oscillating pull of solvent between the vacuum and the IS from the TOPSI. The affect is analyte peaks that are truncated into smaller segments due to the frequent oscillation between the vacuum and IS. A TOPSI system constructed based on arrangement \#4 (data not shown) experimentally confirmed this to be the case. The arrangements \#5-6 the vacuum suction will want to pull solvent away from the ion source resulting in no analyte reaching the mass spectrometer for detection or will prefer to pull air directly from the IS instead of solvent from the TOPSI. Of these six possible arrangements only the options \#1 and \#2 are viable.

In the LVC or SCV operational mode of the TOPSI system two fluids are present in the system (solvent and air). Arrangement \#1 and arrangement \#2 can be further separated into four new flow resistance arrangements (Table S2 and S3 for arrangement \#1 and \#2, respectively).

Table S2. Four possible arrangements of flow resistance through the three capillaries of the TOPSI system when both solvent and air are present based on the \#1 arrangement from 
Table S1 (IS>Vacuum>TOPSI). Red highlighted arrangements indicate arrangements that are unlikely to yield functioning TOPSI designs.

\begin{tabular}{|c|c|c|c|c|c|c|c|}
\hline & & \multicolumn{6}{|c|}{ Resistance in Capillaries when Filled with Solvent (greatest to least) } \\
\hline \multirow{4}{*}{ 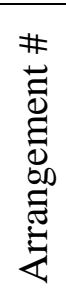 } & 1a & IS Solvent & IS $_{\text {Air }}$ & VacuumSolvent & Vacuum $_{\text {Air }}$ & TOPSI Solvent & TOPSI $_{\text {Air }}$ \\
\hline & $1 \mathrm{~b}$ & IS Solvent & Vacuumsolvent & IS $_{\text {Air }}$ & Vacuum $_{\text {Air }}$ & TOPSI Solvent & TOPSI $_{\text {Air }}$ \\
\hline & $1 \mathrm{c}$ & IS $_{\text {Solvent }}$ & Vacuum $_{\text {Solvent }}$ & TOPSI Solvent & IS $_{\text {Air }}$ & Vacuum $_{\text {Air }}$ & TOPSI $_{\text {Air }}$ \\
\hline & $1 d$ & IS $_{\text {Solvent }}$ & IS $_{\text {Air }}$ & Vacuum $_{\text {Solvent }}$ & TOPSI Solvent & Vacuum $_{\text {Air }}$ & TOPSI $_{\text {Air }}$ \\
\hline
\end{tabular}

Table S2 shows the four possible permutations of arrangement \#1 (Table S1). Due to the physical limitations of the ionization source, permutations \#1a and \#1d were discounted as viable design options. In order to fabricate an ionization source capillary that would have the highest flow resistance of any other capillary whether in air or in solvent, the capillary would have to be very small in diameter. Such a small diameter capillary would have little-to-no self-aspiration flow with the mass spectrometer used here and would result in no analyte signal. Arrangements \#1b and \#1c are possible TOPSI designs and were designated as TOPSI designs \#1 and \#2, respectively, in the main text.

Table S3 shows the four possible permutations of arrangement \#2 (Table S1). Permutations $\# 2 \mathrm{a}, 2 \mathrm{~b}$, and $2 \mathrm{~d}$ all are arranged such that the self-aspiration flow of the ionization source would rather pull flow from the vacuum capillary than from the TOPSI capillary. Thus, these permutations all create a push/pull dynamic between the ionization source and vacuum flows and would likely result in poor performance of the TOPSI. Permutation \#2c is the only option where this push/pull dynamic may be avoided and could be experimentally viable. This permutation was designated as TOPSI design \#3 in the main text.

Table S3. Four possible arrangements of flow resistance through the three capillaries of the TOPSI system when both solvent and air are present based on the \#2 arrangement from Table S1 (IS>TOPSI>Vacuum). Red highlighted arrangements indicate arrangements that are unlikely to yield functioning TOPSI designs.

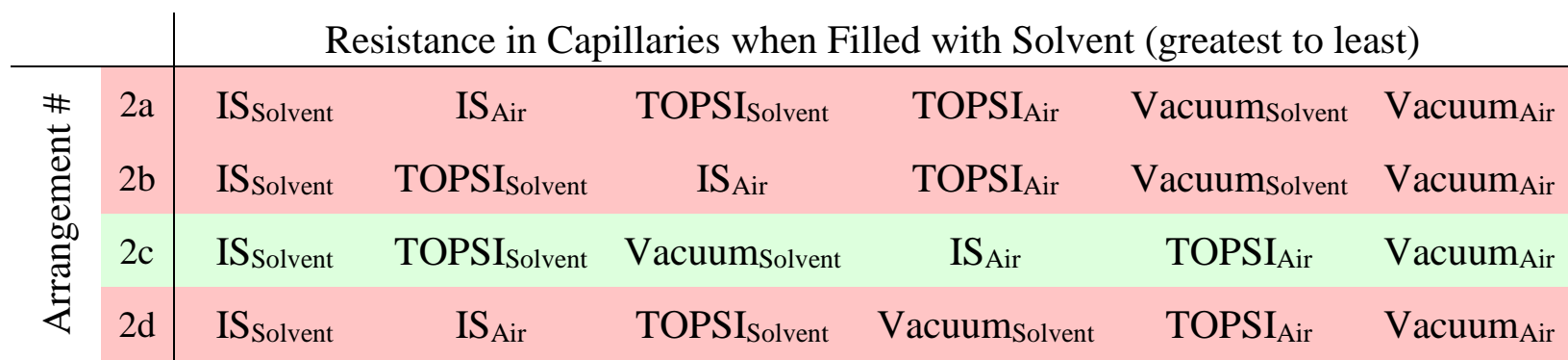


The chosen designs with resistance orderings are found in Table 1 of the main text. The capillary dimensions and calculated flow resistances for the three chosen TOPSI designs are

3 found in Table S4 and Table S5, respectively.

4 Calculation and Estimation of TOPSI Flow Rates Shown in Figure S1

Equation S1 is a modified version of the Hagen-Poiseuille equation used to calculate the flow resistance through a capillary, $\mathrm{R}$ :

$$
R=\frac{8 \mu L}{\pi r^{4}}
$$

Equation S1

7 where $\mu$ is the fluid viscosity, $\mathrm{L}$ denotes the length of the capillary, and $\mathrm{r}$ is the radius of the 8 capillary. By simply changing the diameter of the connecting capillaries (Table S4), a TOPSI 9 system can be created for each flow regime in Table 1. Capillary resistances for each TOPSI 10 variation can be found in Table S5. The calculated resistances were used to model the expected 11 total solvent flow rate and the flow rates through the capillaries to the vacuum (VAC) region and 12 the ionization source (IS) region of the system. Equation S2 determines the solvent flow rate, Q 13 through a capillary:

$$
Q=\frac{\Delta P}{R}
$$

Equation S2

14 where $\Delta \mathrm{P}$ is the difference in pressure between two regions. Using equation $\mathrm{S} 2$ for each pressure 15 differential in the TOPSI, solvent flow can be estimated by Equation S3:

$$
Q_{T O T A L}=\frac{\frac{P_{T O P S I}-P_{I S}}{R_{I S}}+\frac{P_{T O P S I}-P_{V A C}}{R_{V A C}}}{1+\frac{R_{T O P S I}}{R_{I S}}+\frac{R_{T O P S I}}{R_{V A C}}}
$$

16

where $P_{T O P S I}, P_{I S}$, and $P_{V A C}$ are the pressures at the inlet of the TOPSI (1 atm), in the ionization source (IS) region, and at the vacuum outlet, respectively, and $R$ is the resistance through each capillary denoted by the subscript (i.e. IS, VAC, or TOPSI). Briefly, Equation S3 was derived from the equations for total flow resistance of capillaries in series or in parallel:

$$
\text { Capillaries in Series }=R_{1}+R_{2}+\cdots R_{n}
$$

Equation S4

$$
\text { Capillaries in Parallel }=\frac{1}{\frac{1}{R_{1}}+\frac{1}{R_{2}}+\cdots \frac{1}{R_{n}}}
$$

Without the addition of the vacuum region (i.e., where the TOPSI and IS capillaries are in series), the total flow rate $\left(Q_{N o V A C}\right)$ can be estimated by combining Equations S2 and S4. 


$$
Q_{N O V A C}=\frac{P_{T O P S I}-P_{A P C I}}{R_{A P C I}+R_{T O P S I}+R_{T E E}}
$$

Equation S6

The total solvent flow rate through the system $\left(Q_{\text {TотAL }}\right)$ when the vacuum capillary is 2 added in parallel (Equation S3) is derived from Equations S5 and S6.

3 Given an experimentally measured flow rate $(\mathrm{Q}=468 \mu \mathrm{L} / \mathrm{min})$ and total resistance through 4 TOPSI and IS capillaries $\left(6.48 \times 10^{12} \mathrm{~Pa} \cdot \mathrm{s} \cdot \mathrm{m}^{-2}\right.$, Table S4), $P_{I S}$ was estimated to be $49 \mathrm{kPa}$. Total 5 flow rates $\left(Q_{\text {TотAL }}\right)$ for each TOPSI permutation were experimentally determined and used to 6 calculate flow rates through the IS and Vacuum capillaries and estimate the total transport time 7 through the TOPSI system. The flow rate through the IS capillary $\left(Q_{I S}\right)$ was calculated using 8 Equation S7:

$$
Q_{I S}=\frac{P_{T E E}-P_{I S}}{R_{I S}}
$$

9 Where $\mathrm{P}_{\mathrm{TEE}}$ is the pressure in the PEEK tee union region.

10 The flow rate through the vacuum capillary $\left(Q_{V A C}\right)$ was calculated using Equation S8 11 from the values found in Equation S3 and Equation S7.

$$
Q_{V A C}=Q_{T O T A L}-Q_{I S} \quad \text { Equation S8 }
$$

Finally, transport time (TT) through the TOPSI system was estimated using Equation S9.

$$
T T=\frac{V_{T O P S I}}{Q_{T O T A L}}+\frac{V_{T E E}}{Q_{T O T A L}}+\frac{V_{I S}}{Q_{I S}}
$$

Equation S9

13 Where $\mathrm{V}$ is the volume in the capillary denoted by the subscript (TOPSI, TEE, or IS). 
1 Table S4. Inner diameter (ID) and length of the ionization source (IS) capillary, the TOPSI 2 transfer line, and the vacuum line. IS capillary was kept the same for all three TOPSI

3 designs.

\begin{tabular}{lccc}
\hline & & ID $(\mu \mathrm{m})$ & Length $(\mathrm{cm})$ \\
\hline & IS & 152.4 & 14 \\
Design \#1 & TOPSI & 787 & 100 \\
& Vacuum & 254 & 80 \\
Design \#2 & TOPSI & 508 & 100 \\
& Vacuum & 254 & 80 \\
Design \#3 & TOPSI & 508 & 100 \\
& Vacuum & 508 & 80 \\
\hline
\end{tabular}

4

5 Table S5. Calculated flow resistances $\left(\mathrm{Pa} \cdot \mathrm{s} \cdot \mathrm{m}^{-2}\right)$ for methanol and air using equation S1.

6 Values used in equations were taken from Table $\mathbf{S} 4$ for all three tested designs.

\begin{tabular}{lllc}
\hline & & Methanol & Air \\
\hline & IS & $6.18 \times 10^{12}$ & $1.91 \times 10^{11}$ \\
Design \#1 & TOPSI & $6.19 \times 10^{10}$ & $1.92 \times 10^{9}$ \\
& Vacuum & $4.58 \times 10^{12}$ & $1.42 \times 10^{11}$ \\
Design \#2 & TOPSI & $3.57 \times 10^{11}$ & $1.11 \times 10^{10}$ \\
& Vacuum & $4.58 \times 10^{12}$ & $1.42 \times 10^{11}$ \\
Design \#3 & TOPSI & $3.57 \times 10^{11}$ & $1.11 \times 10^{10}$ \\
& Vacuum & $2.86 \times 10^{11}$ & $8.86 \times 10^{9}$ \\
\hline
\end{tabular}



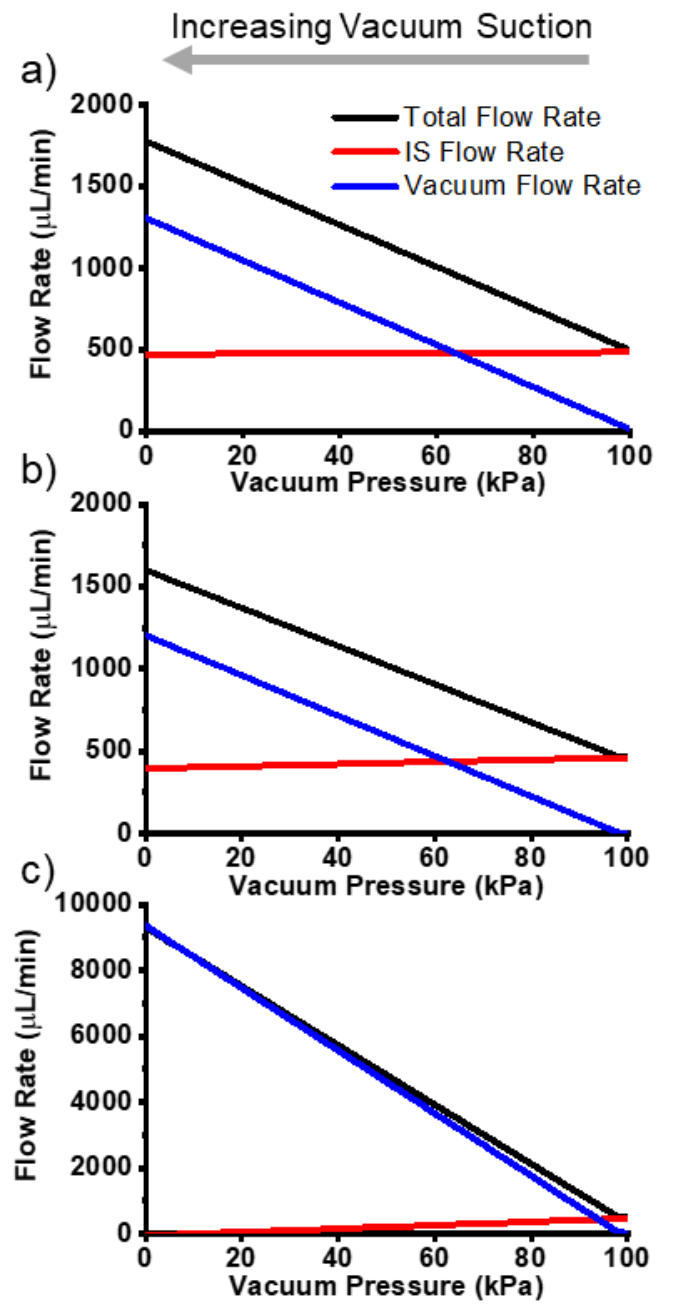

2 Figure S1. Modeled solvent flow rates through the ionization source capillary (red), the 3 vacuum line (blue), and the total solvent flow rate (black) of the TOPSI for design \#1 (a), 4 design \#2 (b), and design \#3 (c). 


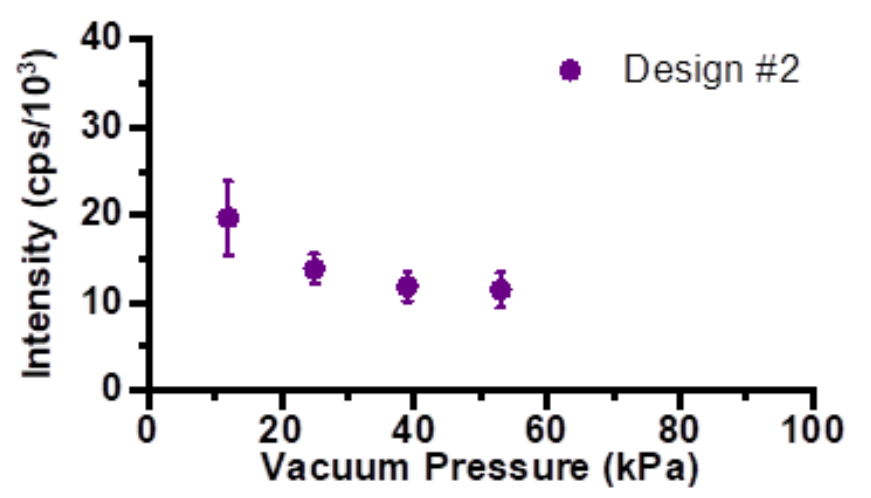

3 Figure S2: Replicate experiment measuring peak height using Design \#2.
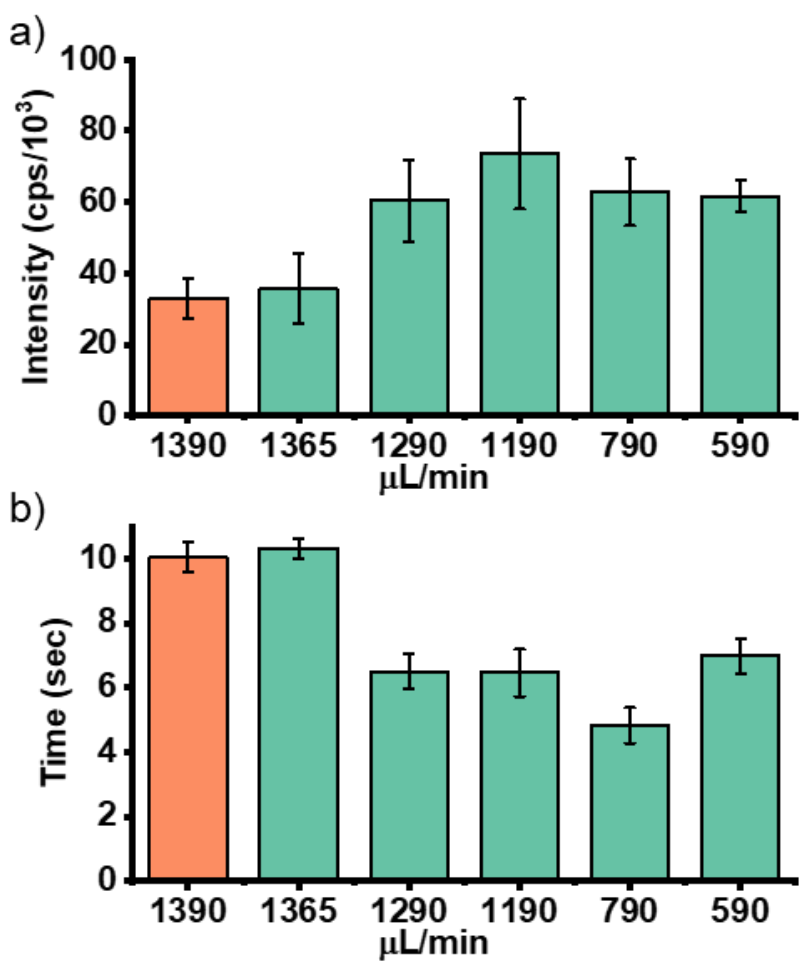

5 Figure S3. a) Peak intensity when analyzing $5 \mathrm{mM}$ propranolol droplets collected at different 6 TOPSI supercritical vortex (SCV) flow rates which results in more air in the system. Orange 7 bar indicates the LVC flow rate and the green designates the various SCV flow rates. b) Peak 8 width at various SCV flow rates (green) below the LVC (orange) flow rate. 
Increasing Vacuum Suction

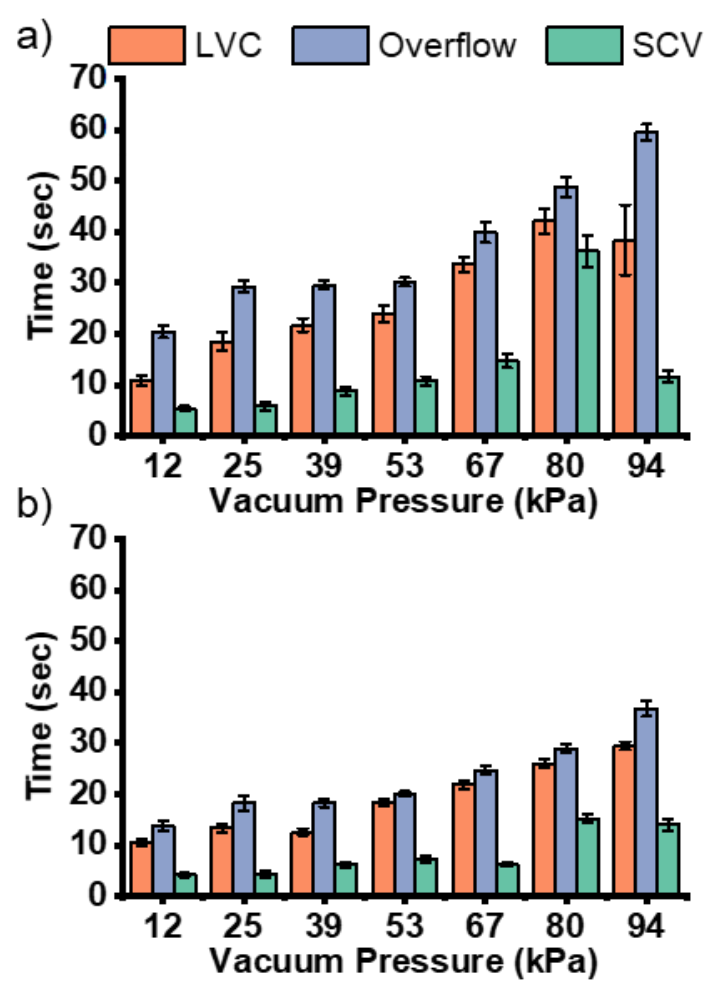

2 Figure S4. Peak widths when analyzing $5 \mathrm{mM}$ droplets of propranolol acquired by the TOPSI 3 in $\mathrm{LVC}(1390 \mu \mathrm{L} / \mathrm{min})$, overflow $(1440 \mu \mathrm{L} / \mathrm{min}$, i.e., $50 \mu \mathrm{L} / \mathrm{min}$ above $\mathrm{LVC}$ flowrate), and $4 \operatorname{SCV}(1190 \mu \mathrm{L} / \mathrm{min}$, i.e., $200 \mu \mathrm{L} / \mathrm{min}$ below $\mathrm{LVC}$ flowrate) mode for design \#1 (a) and design $5 \quad$ \#2 (b) across the vacuum pressure range of $12-94 \mathrm{kPa}$.

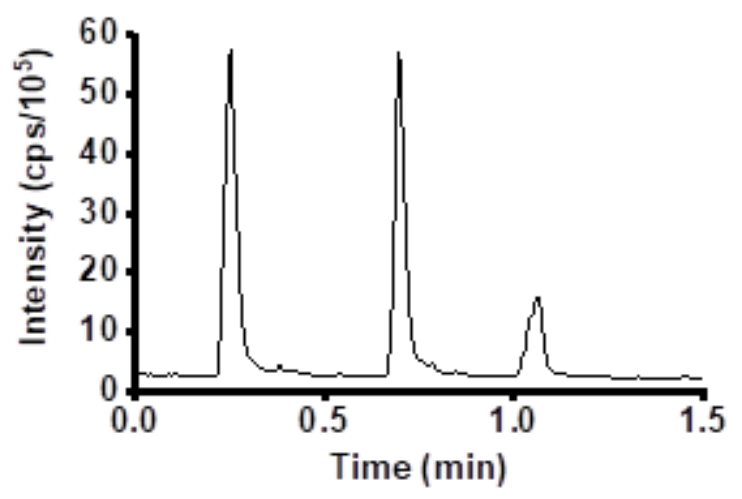

6

$7 \quad$ Figure S5. Chronogram of the analysis of mint leaves using TOPSI. 
a)

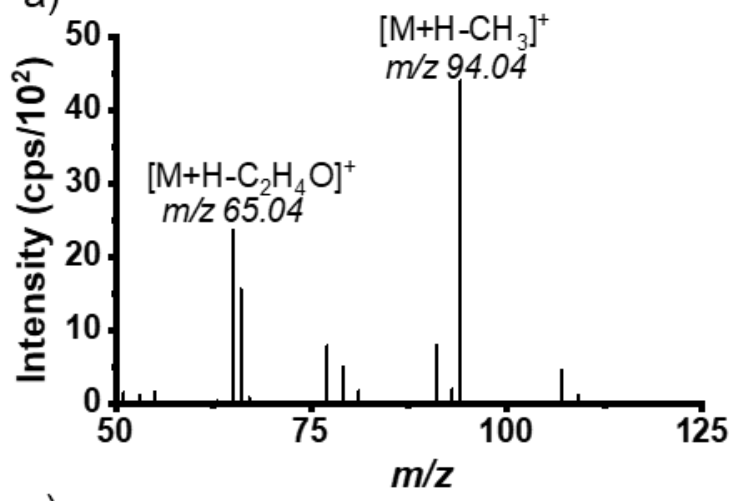

c)

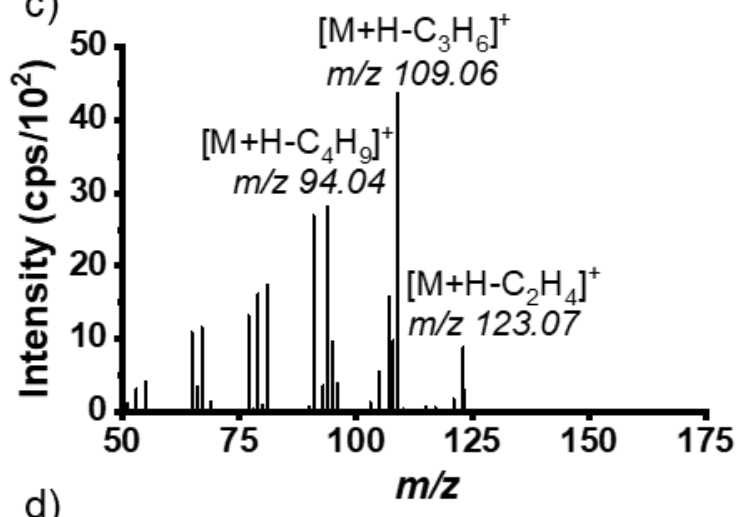

b)

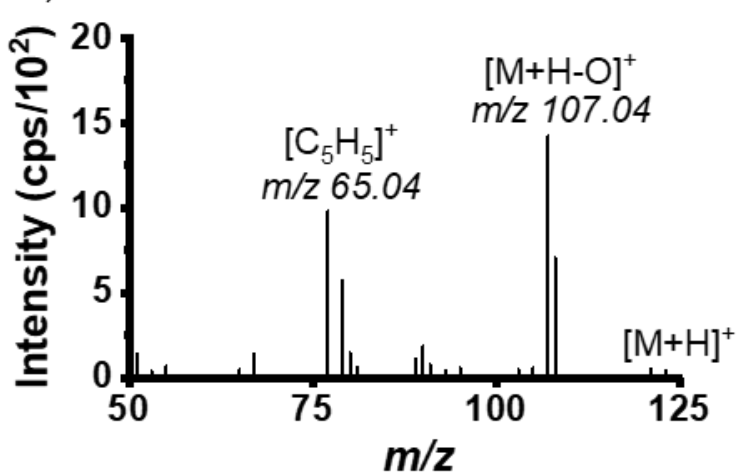

d)

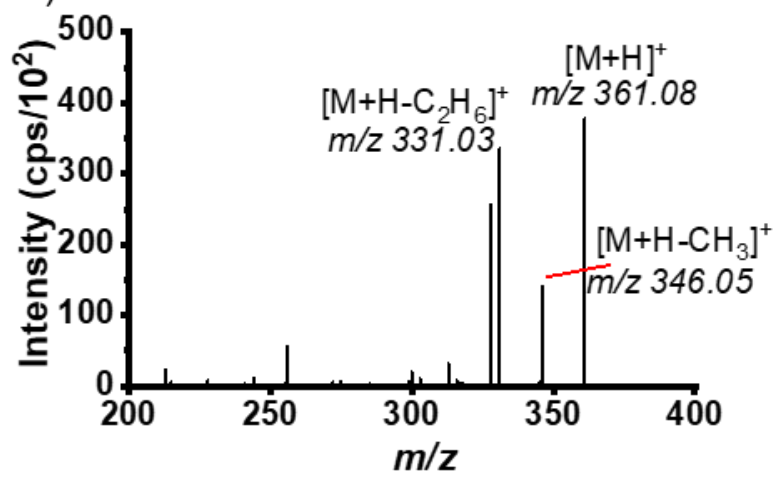

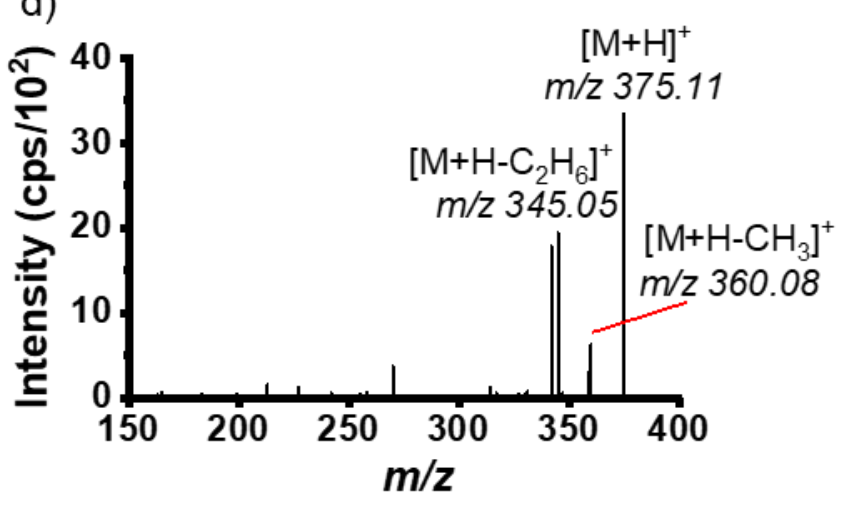

Figure S6: MS/MS of mint extracts identified in positive ion mode (Figure 5a). 3methylphennol, $\mathrm{C}_{7} \mathrm{H}_{8} \mathrm{O}$, showing fragments of the loss of the methyl group and $\mathrm{OH}$ similar to database MS/MS (a). ${ }^{1}$ Tandem MS/MS indicative of ethylphenol (b). Tandem MS of $\mathrm{m} / \mathrm{z}$ 151 with fragment peaks indicative of carvone (c). ${ }^{2}$ The last spectra (d\&e) show the protonated ion for the molecule and subsequent losses of $\mathrm{CH}_{3}$. These molecules formulas were identified as $\mathrm{C}_{12} \mathrm{H}_{24} \mathrm{O}_{12}$ and $\mathrm{C}_{13} \mathrm{H}_{26} \mathrm{O}_{12}$. 
f)

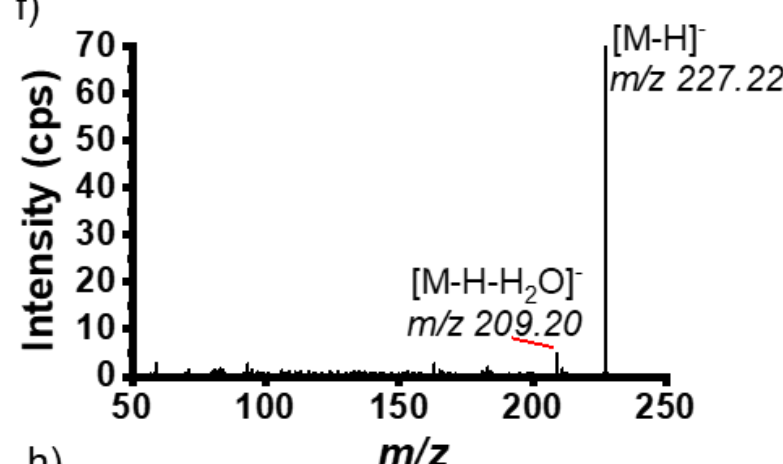

h)

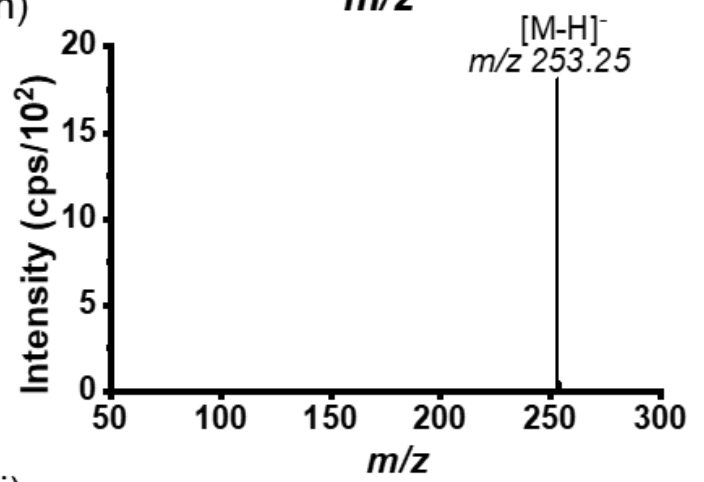

j)

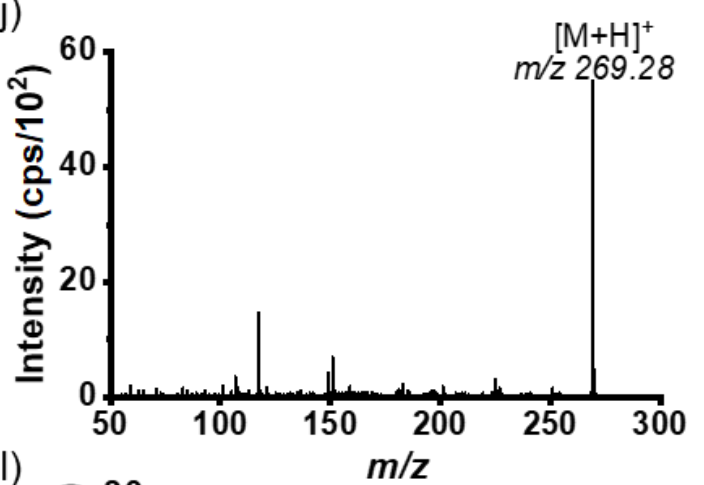

l)

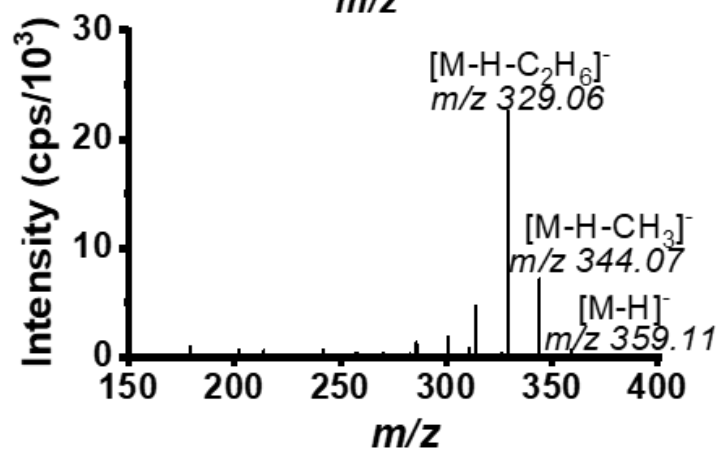

g)

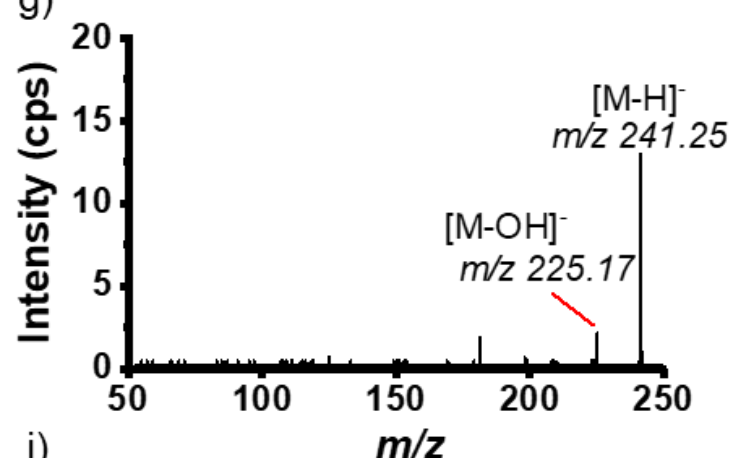

i)

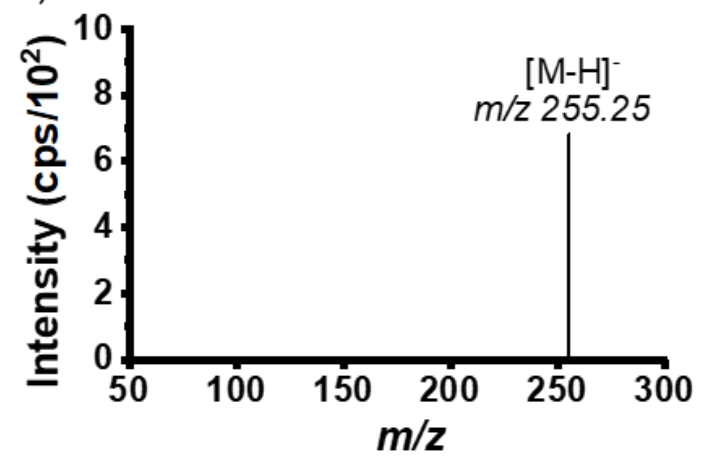

k)

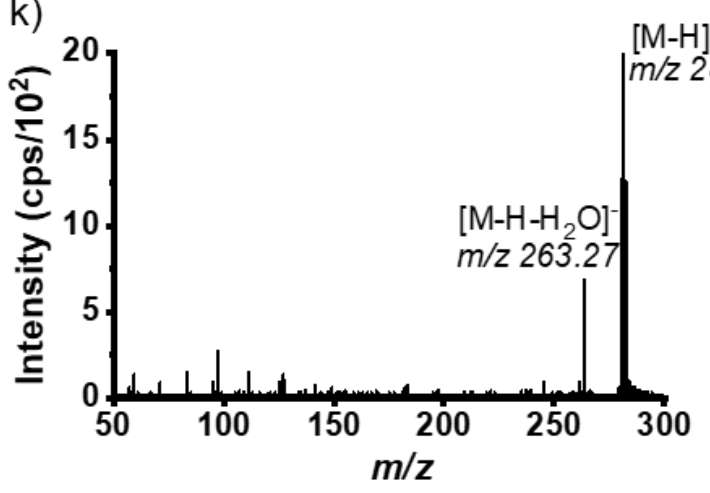

2 Figure S7: MS/MS of mint extracts identified in negative ion mode (Figure 5b). The tandem 3 MS for most of the molecules resulted in little-to-no fragmentation. Based on exact mass 4 though the identified peaks in Figure $5 \mathrm{~b}$ are most likely correct as research shows that these 5 fatty acid chains and fatty acid alcohols are necessary to produce the protective wax layer 6 found on leaves and are common leaf metabolites. ${ }^{3}$ 
o)

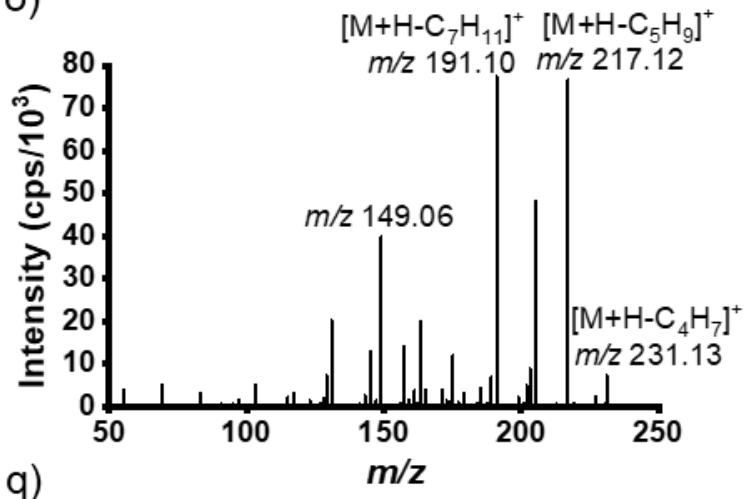

q)

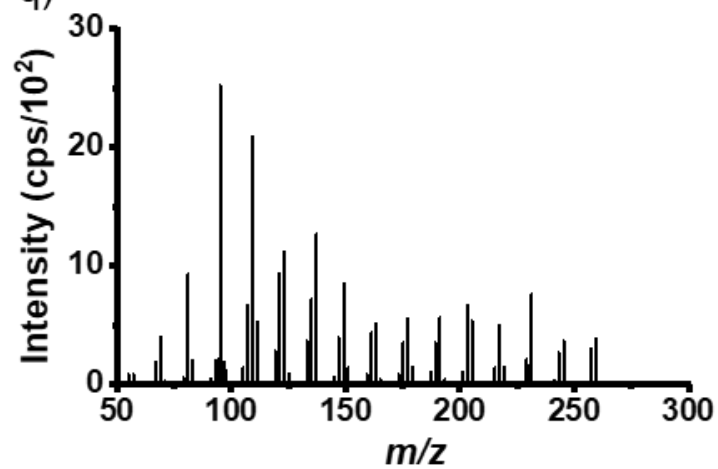

p)

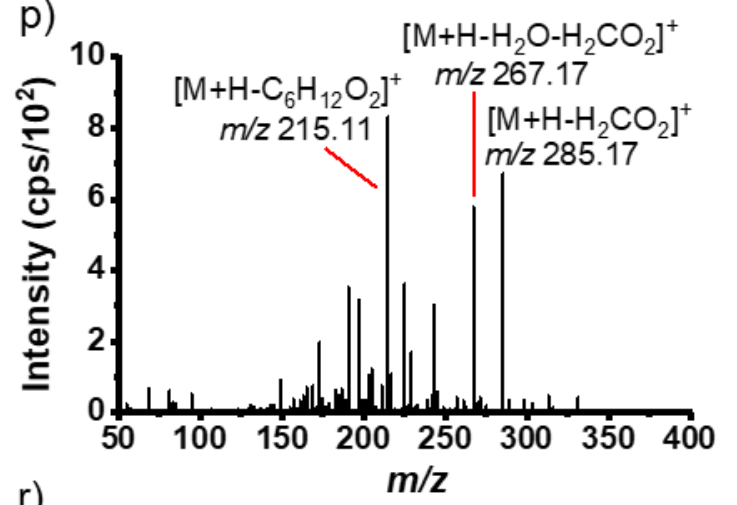

r)

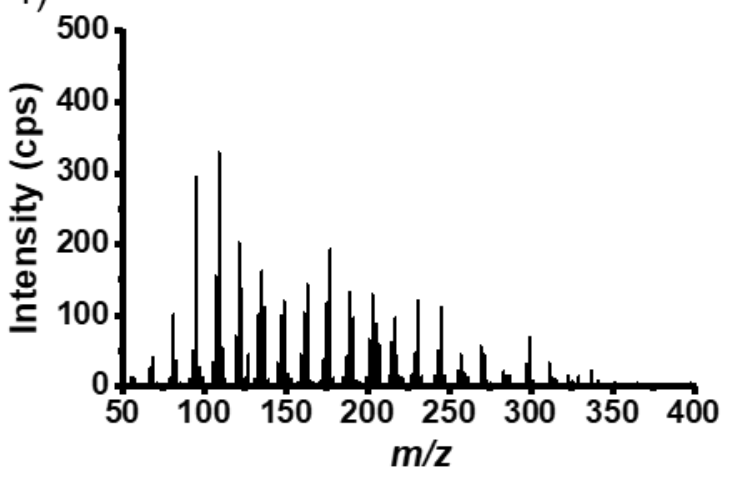

Figure S8: MS/MS of rosemary extracts identified with positive ion mode (Figure 5c). Ferruginol, $\mathrm{C}_{10} \mathrm{H}_{30} \mathrm{O}$, (a) showing fragments indicative of rearrangements proposed by Enzell et al. ${ }^{4}$ and similar fragmentation seen in negative ion mode EI via NIST. ${ }^{1}$ Similarly, carnosol (b) is a common molecule in rosemary and the MS/MS spectrum shows the indicative $\mathrm{m} / \mathrm{z} 285$ peak. ${ }^{5}$ Both the tandem mass spectra for $\mathrm{m} / \mathrm{z} 411$ (q) and $\mathrm{m} / \mathrm{z} 425$ (r) show a pattern indicative of fragmentation of a long carbon chain verifying the identified molecules as octacosanal and octansoic acid. 

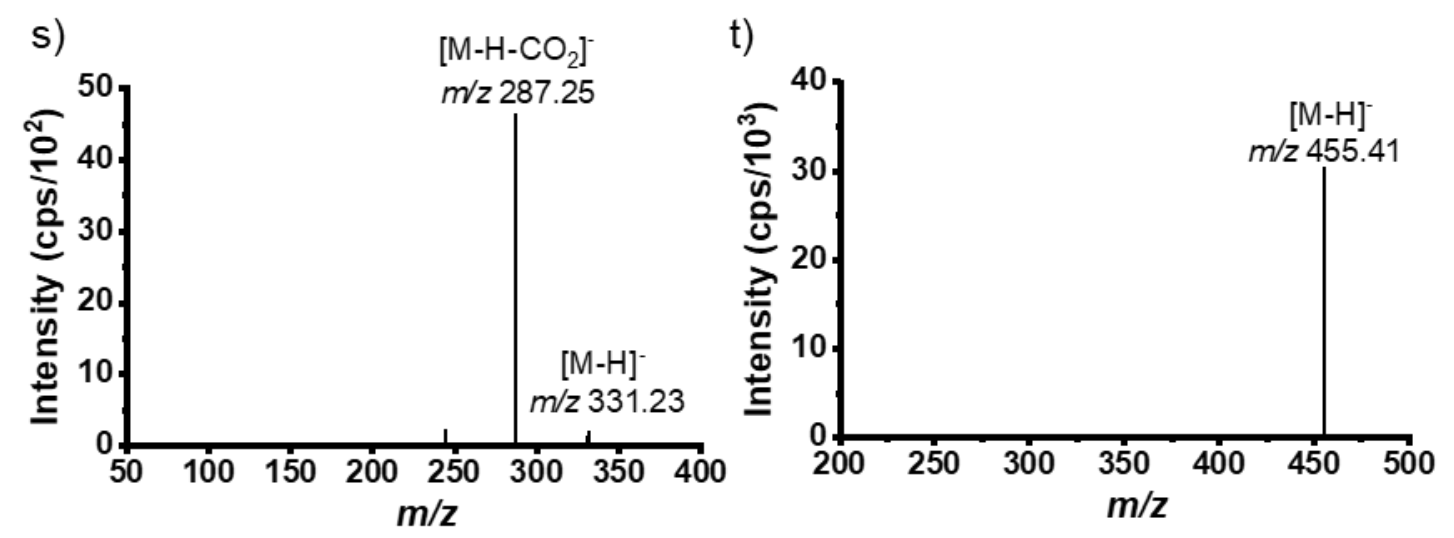

2 Figure S8: MS/MS of rosemary extracts analyzed in negative ion mode (Figure 5d). Carsonic 3 acid, $\mathrm{C}_{20} \mathrm{H}_{28} \mathrm{O}_{4}$, with the indicative loss of $\mathrm{CO}_{2}$ peak (a) and ursolic acid, $\mathrm{C}_{30} \mathrm{H}_{48} \mathrm{O}_{3}$ which 4 exhibited no fragmentation at 25 or 35 CE. ${ }^{5}$

\section{References}

8 1. Wallace, W. E., Mass Spectra. In Nist Chemistry Webbook, Nist Standard Reference

9 Database Number 69, P.J. Linstrom, W. G. M., Ed. National Insititue of Standards and 10 Technology: Gaithersburg MD.

11 2. de Castilho, R. B.; Nunez, C. V.; Lago, A. F.; Santos, A. C. F.; Coutinho, L. H.; Lucas, C. 12 A.; Pilling, S.; Silva-Moraes, M. O.; de Souza, G. G. B., Excitation and Ionic Fragmentation of 13 the Carvone Molecule $\left(\mathrm{C}_{10} \mathrm{H}_{14} \mathrm{O}\right)$ around the $\mathrm{O} 1 \mathrm{~s}$ Edge. J. Electron. Spectrosc. Relat. Phenom. 14 2014, 192, 61-68.

15 3. Soliman, S. S. M.; Abouleish, M.; Abou-Hashem, M. M. M.; Hamoda, A. M.; El-Keblawy, 16 A. A., Lipophilic Metabolites and Anatomical Acclimatization of Cleome Amblyocarpa in the 17 Drought and Extra-Water Areas of the Arid Desert of Uae. Plants 2019, 8 (5), 132.

18 4. C.R. Enzell, I. W., Mass Spectrometric Studies of Diterpenes. Acta Chem. Scand. 1969, 19 23, 871-891.

20 5. Borrás-Linares, I.; Stojanović, Z.; Quirantes-Piné, R.; Arráez-Román, D.; Švarc-Gajić, J.; 21 Fernández-Gutiérrez, A.; Segura-Carretero, A., Rosmarinus Officinalis Leaves as a Natural Source 22 of Bioactive Compounds. Int. J. Mol. Sci. 2014, 15 (11), 20585-20606. 